\title{
Author Correction: Radiation-activated secretory proteins of Scgbla1+ club cells increase the efficacy of immune checkpoint blockade in lung cancer
}

Yi Ban, Geoffrey J. Markowitz (D), Yue Zou, Divya Ramchandani, Jeffrey Kraynak, Jianting Sheng, Sharrell B. Lee, Stephen T. C. Wong (1), Nasser K. Altorki (D), Dingcheng Gao (i) and Vivek Mittal (1)

Correction to: Nature Cancer https://doi.org/10.1038/s43018-021-00245-1, published online 20 September 2021.

In the version of this article initially published, there was an error in the Acknowledgements section. An extraneous listing of a grant has now been removed.

Published online: 12 January 2022

https://doi.org/10.1038/s43018-022-00330-z

( The Author(s), under exclusive licence to Springer Nature America, Inc. 2022 